\title{
Prostacyclin receptor-induced STAT3 phosphorylation in human erythroleukemia cells is mediated via $G \alpha_{s}$ and $G \alpha_{16}$ hybrid signaling
}

\author{
Rico K.H. Lo ${ }^{1}$, Andrew M.F. Liu ${ }^{1}$, Helen Wise ${ }^{2}$ and Yung H. Wong ${ }^{1}$ \\ ${ }^{1}$ Department of Biochemistry, Molecular Neuroscience Center, and Biotechnology Research \\ Institute, Hong Kong University of Science and Technology, Clear Water Bay, Kowloon, Hong \\ Kong, China.
}

${ }^{2}$ Department of Pharmacology, Faculty of Medicine, The Chinese University of Hong Kong, Shatin, New Territories, Hong Kong, China. 


\section{RUNNING TITLE}

$\mathrm{G} \alpha_{\mathrm{s}}$ alters $\mathrm{G} \alpha_{16}$-induced STAT3 phosphorylations

\section{Corresponding Author}

Dr. Yung H. Wong

Department of Biochemistry, Molecular Neuroscience Center, and Biotechnology Research Institute, Hong Kong University of Science and Technology, Clear Water Bay, Kowloon, Hong Kong, China.

Tel: +852-2358-7328. Fax: +852-2358-1552. E-mail: boyung@ust.hk

Text Page: 36

Table: 0

References: 40

\section{Abstract: 249}

Introduction: 750

Discussion: 1426

\section{ABBREVIATIONS}

AC, adenylyl cyclase; cAMP, cyclic AMP; CTX, cholera toxin; C5aR, C5a Receptor; DB-cAMP, dibutyryl-cAMP; ERK, extracellular signal-regulated kinase; FBS, fetal bovine serum; GPCRs, G protein-coupled receptors; HEL, human erythroleukemia; HEK, human embryonic kidney; hIP, human prostacyclin receptor; JAK, Janus kinase; JNK, c-Jun N-terminal kinase; MEM, minimum essential medium; MEK, MAPK/ERK kinase; PGI $_{2}$, prostacyclin; PI3K, phosphatidylinositol-3 kinase; PLC $\beta$, phospholipase C $\beta$; PKA, protein kinase A; PTX, pertussis toxin; STAT3, signal transducer and activator of transcription 3. 


\section{ABSTRACT}

Human prostacyclin receptor (hIP) can stimulate STAT3 via pertussis toxin-insensitive G proteins in human erythroleukemia (HEL) cells. Since hIP can utilize $G_{s}$ and $G_{q}$ proteins for signal transduction and that both G proteins can induce STAT3 phosphorylation and activation via complex signaling networks, we sought to determine if one of them is predominant in mediating the hIP signal. Stimulation of STAT3 $\mathrm{Tyr}^{705}$ and $\mathrm{Ser}^{727}$ phosphorylations by the IP-specific agonist, cicaprost, was sensitive to inhibition of protein kinase A, phospholipase C $\beta$, protein kinase C, calmodulin-dependent protein kinase II and Janus kinase 2/3. Unlike G $\alpha_{16}$-mediated regulation of STAT3 in the same cells (Lo et al., J. Biol. Chem. 2003, 278: 52154-52165), cicaprost-induced STAT3 $\mathrm{Tyr}^{705}$ phosphorylation was resistant to inhibition of Src and MEK while STAT3 $\operatorname{Ser}^{727}$ phosphorylation distinctly required phosphatidylinositol-3 kinase. This unique inhibitor-sensitivity pattern of STAT3 phosphorylation was reproduced in HEL cells by stimulating the $\mathrm{G}_{16}$-coupled $\mathrm{C} 5 \mathrm{a}$ receptor in the presence of dibutyryl-cAMP, suggesting that the change in inhibitor-sensitivity was due to activation of the $\mathrm{G}_{\mathrm{s}}$ pathway. This postulation was further confirmed by expressing constitutively active $G \alpha_{16} \mathrm{QL}$ and $\mathrm{G} \alpha_{\mathrm{s}} \mathrm{QL}$ in human embryonic kidney 293 cells. Thus, the inhibitor-sensitivity of $\mathrm{G}_{16} \mathrm{QL}$-induced STAT3 phosphorylations could be converted by the mere presence of $G \alpha_{s} \mathrm{QL}$ to resemble that obtained with cicaprost in HEL cells. Taken together, our observations illustrate that co-stimulation of $\mathrm{G}_{\mathrm{s}}$ and $\mathrm{G}_{\mathrm{q}}$ can result in the fine-tuning of STAT3 activation status, and this may provide the basis for cell type-specific responses following activation of hIP. 


\section{INTRODUCTION}

G protein-coupled receptors (GPCRs) are a group of diverse and multifunctional signal detectors for cellular communication and practically all GPCRs possess the ability to simultaneously activate multiple $G$ proteins. For instance, many GPCRs that signal via $G_{s}$ to elevate intracellular cAMP level can also regulate other signal transduction pathways through $\mathrm{G}_{\mathrm{i}}$ or $G_{q}$ proteins. Even the prototypical $G_{s}$-coupled $\beta_{2}$-adrenergic receptor can employ $G_{i}$ proteins for signaling (Daaka et al., 1997; Hasseldine et al., 2003). However, the cellular and biological implications of co-stimulating multiple G proteins by any particular GPCR are poorly understood. An array of $G$ protein signals would confer signal diversity at the expense of fidelity. There is evidence to suggest that co-stimulation of multiple G protein-dependent pathways would allow GPCRs to regulate cellular events that are otherwise non-responsive (Ryzhov et al., 2006).

Several $G_{s}$-coupled receptors are able to activate $G_{s}$ and $G_{q}$ proteins simultaneously, leading to the stimulation of adenylyl cyclase (AC) and phospholipase C $\beta$ (PLC $\beta$ ). They include the vasopressin $V_{2}$ (Schoneberg et al., 1998) and prostacyclin (Chow et al., 2004; Kam et al., 2001) receptors. Prostacyclin (prostaglandin $\mathrm{I}_{2}$ ), the primary product of cyclooxygenase-2 (McAdam et al., 1999), is the endogenous ligand of the prostacyclin receptor (IP). IP is expressed in vascular tissue, platelets, kidney, dorsal root ganglia, lymphocytes and megakaryocytes (Narumiya et al., 1999). Mimetics such as cicaprost have been developed with improved biological and metabolic stability. They are potent vasodilators, with antithrombotic and antiplatelet activity (Belch et al., 1993) and are clinically useful for pulmonary hypertension (Rubin et al., 1982). Prostacyclin, but not cicaprost, also plays a role in adipocyte differentiation, embryo implantation, and apoptosis (Wise, 2003). 
The downstream signaling capacity of IP has tended to focus on the extracellular signal-regulated kinase (ERK) pathway. In vascular smooth muscle cells, human IP (hIP) inhibits ERK via protein kinase A (PKA) (Zucker et al., 1998), but in preadipocytes, its activation results in PKA-dependent ERK stimulation (Belmonte et al., 2001). In Chinese hamster ovary cells transiently expressing IP, cicaprost activated ERK through $\mathrm{G}_{\mathrm{q} / 11} / \mathrm{PLC} \beta / \mathrm{PKC}$ and phosphatidylinositol-3 kinase (PI3K) but not via cAMP/PKA (Chu et al., 2004). Also, stimulatory phosphorylations of ERK and c-Jun $\mathrm{N}$ terminal protein kinase (JNK), but not p38 MAPK, have been observed in human erythroleukemia (HEL) cells upon activation of hIP (Lo et al., 2006). We have recently demonstrated that cicaprost induces $\mathrm{Tyr}^{705}$ and $\mathrm{Ser}^{727}$ phosphorylations of signal transducer and activator of transcription 3 (STAT3) via pertussis toxin (PTX)-insensitive G proteins in HEL cells (Lo et al., 2006). However, although both ERK and STAT3 are predominantly associated with cell proliferation, GPCR-stimulated ERK is not functionally associated with proliferation in HEL cells (Wu et al., 2002). Therefore, the ability of hIP to activate STAT3 in HEL cells may rather provide a linkage to the control of differentiation by prostacyclin, since megakaryocytic/erythroid cell maturation accompanies an enhancement of IP expression (Sasaki et al., 1997).

STAT3 can be activated by several G $\alpha$ subunits including pertussis toxin (PTX)-sensitive $\mathrm{G} \alpha_{\mathrm{o}}$ and $\mathrm{G} \alpha_{\mathrm{i} 2}$ (Ram et al., 2000) and PTX-insensitive G $\alpha_{\mathrm{s}}$ (Liu et al., 2006), G $\alpha_{16}$ (Lo et al., 2003), and $\mathrm{G \alpha}_{14}$ (Lo and Wong, 2004). In HEL cells, the $\mathrm{G}_{16}$-coupled complement C5a receptor (C5aR) activates STAT3 through multiple pathways including the PLC $\beta / P K C / R a f-1 / M E K / E R K$ axis (Lo et al., 2003). Since hIP can stimulate PLC $\beta$ (Chow et al., 2004; Kam et al., 2001), the same pathway is presumably in operation upon activation of hIP in HEL cells. Surprisingly, inhibition of MEK by U0126 failed to block cicaprost-induced STAT3 $\mathrm{Tyr}^{705}$ phosphorylation in 
HEL cells (Lo et al., 2006), but the same treatment effectively inhibited C5a-induced STAT3 $\mathrm{Tyr}^{705}$ and $\mathrm{Ser}^{727}$ phosphorylations (Lo et al., 2003). This intriguing observation points to additional regulatory control of hIP-activated STAT3 activity since $\mathrm{Tyr}^{705}$ phosphorylation is required for STAT3 transcriptional activity (Darnell, 1997). The differential dependency of C5aand cicaprost-induced STAT3 $\mathrm{Tyr}^{705}$ phosphorylation on MEK may arise from the differences in specificity of receptor/G protein interactions; $G_{s} / G_{q}$ versus $G_{i} / G_{16}$ for hIP and C5aR, respectively. Indeed, our recent study revealed that $\mathrm{G}_{\mathrm{s}}$-induced STAT3 $\mathrm{Tyr}^{705}$ phosphorylation is resistant to blockade of the Raf/MEK/ERK pathway (Liu et al., 2006). In this present study, we tested the hypothesis that activation of $\mathrm{G}_{\mathrm{s}}$ and $\mathrm{G}_{\mathrm{q}}$ by hIP confers upon the receptor an alternative pathway to stimulate STAT3. We were able to demonstrate that, in the presence of activated $G \alpha_{s}$, the pattern of $\mathrm{G} \alpha_{16}$-mediated STAT3 phosphorylation was altered with regard to its dependence on MEK, Src and PI3K; thus resembling the characteristics of STAT3 activation following stimulation of hIP in HEL cells. 


\section{MATERIALS AND METHODS}

\section{Reagents}

Cicaprost was a gift from Schering AG, Berlin, Germany. The cDNAs of human G proteins were purchased from Guthrie Research Institute (Sayre, PA) and hIP was a gift from Prof. S. Narumiya (Kyoto University, Japan). Cell culture reagents, including LipofectAMINE PLUS reagents, were obtained from Invitrogen (Carlsbad, CA). Stealth Select RNAi targeting G $\alpha_{s}$ and Stealth RNAi Negative Control Med GC were also purchased from Invitrogen where HiPerfect was a product of Qiagen (Germantown, MD, USA).All kinase inhibitors and their negative analogues as well as Rp-cAMPS and dibutyryl-cAMP (DB-cAMP) were purchased from Calbiochem (Darmstadt, Germany). C5a and cholera toxin (CTX) were purchased from Sigma Aldrich (St. Louis, MO). PTX was obtained from List Biological Laboratories (Campbell, CA). c-Src antiserum was from Santa Cruz (Santa Cruz, CA) and other antisera were purchased from Cell Signaling (Beverly, MA). Nitrocellulose membrane and ECL kit were purchased from Bio-Rad Laboratories (Hercules, CA) and Amersham (Piscataway, NJ), respectively. The myo- $\left[{ }^{3} \mathrm{H}\right]$ inositol was from NEN (Boston, MA). The luciferase reporter gene, pSTAT3-TA-luc, was from Clontech laboratories, Inc (Palo Alto, CA). The luciferase substrate and its lysis buffer were purchased from Roche Diagnostics (Mannheim, Germany).

\section{Cell Culture and Transfection}

HEL cells were obtained from German Collection of Microorganisms and Cell Cultures (ACC11, Braunschweig, Germany) and were cultured in RPMI 1640 at $5 \% \mathrm{CO}_{2}, 37^{\circ} \mathrm{C}$ with $10 \%$ fetal bovine serum (FBS), 50 units/ml penicillin and $50 \mu \mathrm{g} / \mathrm{ml}$ streptomycin. Human embryonic kidney 293 (HEK293) cells were purchased from the American Type Culture Collection 
(CRL-1573, Rockville, MD, USA) and were grown in Eagle's minimum essential medium (MEM) at $5 \% \mathrm{CO}_{2}, 37^{\circ} \mathrm{C}$ with $10 \% \mathrm{FBS}, 50$ units/ml penicillin and $50 \mu \mathrm{g} / \mathrm{ml}$ streptomycin. For G $\alpha_{\mathrm{s}}$ knockdown, $3 \times 10^{5}$ HEL cells were first resuspended in RPMI with $10 \%$ FBS. The transfection cocktail was prepared by mixing 180 pmol Stealth Select RNAi targeting Go $\alpha_{\mathrm{s}}$ or control RNAi using $9 \mu \mathrm{L}$ HiPerfect reagent in $100 \mu \mathrm{L}$ serum-free RPMI. After 6 h, $400 \mu \mathrm{L}$ RPMI with $10 \%$ FBS was added.

\section{Western Blotting Analysis}

HEL cells were seeded at a density of $1 \times 10^{6}$ cells/ml using serum-free RPMI medium and treated with PTX (100 ng/ml) overnight. Cells were then pre-treated with different kinase inhibitors or vehicle control (0.1\% DMSO) for $30 \mathrm{~min}$ and then incubated with $100 \mathrm{nM}$ cicaprost alone or with other drugs as indicated for another $30 \mathrm{~min}$ at $37^{\circ} \mathrm{C}$. HEK293 cells were seeded on 6-well plates at a density of $5 \times 10^{5}$ cells/well and were cultured in the growth medium for 18 to $24 \mathrm{~h}$ prior to transfection. They were co-transfected with various cDNAs using LipofectAMINE PLUS reagents as described previously (Lo et al., 2003), and tested $48 \mathrm{~h}$ post-transfection. HEK293 cells were serum-starved overnight, and incubated with different kinase inhibitors for 30 min prior to cell lysis. Cell lysates were prepared, resolved on $12 \%$ SDS-polyacrylamide gels, and transferred to Osmonics nitrocellulose membrane as described previously (Liu and Wong, 2005). STAT3, phospho-STAT3-Tyr ${ }^{705}$, phospho-STAT3-Ser ${ }^{727}$, c-Src, phospho-c-Src, Janus kinase (JAK) 2 and phospho-JAK2, Akt, phospho-Akt-Thr ${ }^{308}$ proteins were detected by specific primary antisera and horseradish peroxidase-conjugated secondary antisera. The immunoblots were visualized by chemiluminescence with the ECL kit, and the images detected in X-ray films 
were quantified by densitometric scanning using the Eagle Eye II still video system (Stratagene, La Jolla, CA).

\section{Inositol Phosphates Accumulation Assay}

HEK293 cells were plated into 12-well plates at $1.5 \times 10^{5}$ cells/well. Cells were transiently transfected with various cDNAs using LipofectAMINE PLUS reagents as described previously (Lo et al., 2003). On the following day, cells were labeled with $750 \mu \mathrm{l}$ of inositol-free MEM with 5\% FBS and $2.5 \mu \mathrm{Ci} / \mathrm{ml}$ myo- $\left[{ }^{3} \mathrm{H}\right]$ inositol for $18-24 \mathrm{~h}$ with the addition of $100 \mathrm{ng} / \mathrm{ml}$ PTX. The labeling medium was aspirated and replaced with $1 \mathrm{ml}$ assay medium (20 mM HEPES-buffered MEM with $5 \mathrm{mM} \mathrm{LiCl)} \mathrm{for} 10 \mathrm{~min}$, and then cells were treated with or without $10 \mathrm{nM}$ cicaprost at $37^{\circ} \mathrm{C}$ for $1 \mathrm{~h}$. Cell extracts were prepared and then subjected to ion-exchange chromatography to separate $\left[{ }^{3} \mathrm{H}\right]$ inositol phosphates from other labeled inositol species as described previously (Tsu et al., 1995). The inositol phosphate levels were determined as the average ratio of $\left[{ }^{3} \mathrm{H}\right]$ inositol phosphates to the total $\left[{ }^{3} \mathrm{H}\right]$ inositol species. Variations of triplicates within a given experiment were less than $10 \%$.

\section{Luciferase Assay}

HEK293 cells were seeded in 96-well microtiter plates at $1.5 \times 10^{4}$ cells/well and cultured in MEM medium plus 10\% FBS overnight. Cells were transiently co-transfected with various cDNAs using LipofectAMINE PLUS reagents as described previously (Lo et al., 2003). Transfectants were serum-starved and treated with different kinase inhibitor overnight as appropriate. Cell lysates were collected and analyzed as described previously (Liu et al., 2006). 


\section{RESULTS}

Participation of $\mathrm{G} \alpha_{\mathrm{s}}$ and AC/PKA in cicaprost-induced STAT3 phosphorylations in HEL cells

Our previous report illustrated the ability of cicaprost to induce STAT3 phosphorylations in HEL cells, with an EC $_{50}$ value of approximately 30 nM (Lo et al., 2006). Recently, CAY 10449 has been identified as a potent IP antagonist (Clark et al., 2004). CAY 10449 was therefore employed to confirm the requirement of hIP in cicaprost-induced STAT3 $\mathrm{Tyr}^{705}$ and $\mathrm{Ser}^{727}$ phosphorylations. HEL cells were pre-treated throughout this study with $100 \mathrm{ng} / \mathrm{ml}$ PTX for $16 \mathrm{~h}$, to eliminate possible interference from $\mathrm{G}_{\mathrm{i} / \mathrm{o}}$ proteins, and serum-starved before testing. HEL cells were incubated for $30 \mathrm{~min}$ with $100 \mathrm{nM}$ cicaprost in the absence or presence of CAY 10449 (1 $\mu \mathrm{M})$. Crude lysates were then resolved and immunoblotted with anti-STAT3, anti-phospho-STAT3-Tyr ${ }^{705}$ and anti-phospho-STAT3-Ser ${ }^{727}$ antisera. As described previously (Lo et al., 2006), cicaprost significantly stimulated STAT3 $\mathrm{Tyr}^{705}$ and $\mathrm{Ser}^{727}$ phosphorylations in HEL cells (Fig. 1A). In addition, CAY 10449 alone had no effect on either the basal levels of $\mathrm{Tyr}^{705}$ and $\mathrm{Ser}^{727}$ STAT3 phosphorylations or the total STAT3 proteins while it completely abrogated the cicaprost-induced STAT3 phosphorylations. The use of CAY 10449 thus validated the specific role of hIP in cicaprost-induced STAT3 responses.

Since hIP primarily couples to G $\alpha_{\mathrm{s}}$ (Miggin and Kinsella, 2002) and constitutively active G $\alpha_{s} \mathrm{QL}$ is able to activate STAT3 in a PKA-dependent manner (Liu et al., 2006), we asked whether the cicaprost-induced STAT3 responses in HEL cells were $\mathrm{G}_{\mathrm{s}}$-dependent. To examine the involvement of $G \alpha_{\mathrm{s}}$-mediated pathway, we incubated HEL cells for 30 min with Rp-cAMPS or $\mathrm{H}-89$, two kinase inhibitors that target protein kinase A (PKA). They were then exposed to 100 
$\mathrm{nM}$ cicaprost challenge for $30 \mathrm{~min}$ and the crude lysates were probed for STAT3 phosphorylations. Inhibition of PKA by $100 \mu \mathrm{M}$ Rp-cAMPS or $10 \mu \mathrm{M} \mathrm{H}-89$ completely abrogated the cicaprost-induced STAT3 phosphorylations (Fig. 1B). Moreover, treatment of HEL cells with either $1 \mu \mathrm{M}$ cholera toxin (CTX, which ADP-ribosylates and activates G $\alpha_{\text {s }}$ proteins) or $1 \mathrm{mM}$ DB-cAMP (which preferentially activates cAMP-dependent protein kinases) led to significant $\mathrm{Tyr}^{705}$ and $\mathrm{Ser}^{727}$ STAT3 phosphorylations (Fig. 1B). Treatment with these inhibitors or activators did not affect the expression of the total STAT3 proteins in HEL cells as compared to the control (Fig. 1B). These results illustrate that cicaprost-induced STAT3 activation in HEL cells might be mediated through $\mathrm{G}_{\mathrm{s}}$ and PKA.

\section{Coupling of hIP to $\mathrm{G} \alpha_{q}, \mathrm{G} \alpha_{11}$ and $\mathrm{G} \alpha_{16}$, but not $\mathrm{G} \alpha_{14}$, for STAT3 activation}

Apart from $G \alpha_{s}$, hIP can also utilize $G_{q / 11}$ proteins for signaling (Chow et al., 2004). One particular feature of HEL cells is the endogenous expression of both $G \alpha_{16}$ and $G \alpha_{14}$, members of the $G_{q}$ family of $G$ proteins (Lo et al., 2003; Lo and Wong, 2004). Since these promiscuous $G \alpha$ subunits (Ho et al., 2001; Offermanns and Simon, 1995) are capable of mediating GPCR-induced activation of STAT3 (Lo et al., 2003; Lo and Wong, 2004), they could provide a functional linkage between hIP and STAT3. We thus adopted a well established transient recombinant system (Yung et al., 1999) to examine the ability of these PTX-insensitive $G_{q}$ proteins to interact with hIP. HEK293 cells were transiently co-transfected with hIP alone or in combination with $\mathrm{G} \alpha_{\mathrm{q}}, \mathrm{G} \alpha_{11}, \mathrm{G} \alpha_{16}$ or $\mathrm{G} \alpha_{14}$. Functional coupling with any of these $\mathrm{G} \alpha$ subunits would be reflected in enhanced formation of inositol phosphates by cicaprost. As shown in Fig. 2A, $10 \mathrm{nM}$ cicaprost significantly stimulated PLC $\beta$ activity in the hIP-expressing cells, and this response was further enhanced by $G \alpha_{q}, G \alpha_{11}$ and $G \alpha_{16}$, but not by $G \alpha_{14}$. As no enhancement of cicaprost-induced 
PLC $\beta$ activity could be detected in cells co-expressing hIP and $\mathrm{G \alpha}_{14}$ (Fig. 2A), it is unlikely that hIP interacts with $G \alpha_{14}$. Since expression of the constitutively active mutants of $G \alpha_{q}, G \alpha_{11}, G \alpha_{16}$ and $\mathrm{G \alpha}_{14}$ in HEK293 cells all resulted in the stimulation of PLC $\beta$ activities (data not shown but similar to those reported previously), activation of the corresponding wildtype G $\alpha$ subunits by hIP should lead to increased inositol phosphates formation. Taken together, our results indicate that hIP is capable of employing $G \alpha_{q}, G \alpha_{11}$ and $G \alpha_{16}$, but not $G \alpha_{14}$, for signal transduction in HEK293 cells, and such functional interactions would presumably hold true in HEL cells where these components are endogenously expressed.

The abilities of $\mathrm{G} \alpha_{16}$ and $\mathrm{G} \alpha_{14}$ to activate STAT3 have previously been demonstrated (Lo et al., 2003; Lo and Wong, 2004). To determine whether $\mathrm{G} \alpha_{\mathrm{q}}$ and $\mathrm{G} \alpha_{11}$ can also mediate STAT3 $\mathrm{Tyr}^{705}$ and $\mathrm{Ser}^{727}$ phosphorylations, HEK293 cells were transiently transfected with the wildtype or constitutively active mutants of $\mathrm{G} \alpha_{\mathrm{q}}\left(\mathrm{G} \alpha_{\mathrm{q}} \mathrm{RC}\right), \mathrm{G} \alpha_{11}\left(\mathrm{G} \alpha_{11} \mathrm{QL}\right)$ and $\mathrm{G} \alpha_{16}\left(\mathrm{G} \alpha_{16} \mathrm{QL}\right)$. As shown in Fig. 2B, G $\alpha_{\mathrm{q}} \mathrm{RC}$ and $\mathrm{G} \alpha_{11} \mathrm{QL}$ significantly induced STAT3 $\mathrm{Tyr}^{705}$ and $\mathrm{Ser}^{727}$ phosphorylations as compared to their wildtype and pcDNA1 controls. $G \alpha_{16} \mathrm{QL}$ was employed as a positive control in this experiment. No change in total STAT3 was detected in any of the transfectants (Fig. 2B). These findings indicate that activated $G \alpha_{q}, G \alpha_{11}$ and $G \alpha_{16}$ can induce the phosphorylations of STAT3. In order to identify a similar correlation between $\mathrm{G} \alpha_{\mathrm{q}} \mathrm{RC}$ - and G $\alpha_{11}$ QL-induced STAT3 phosphorylations and modulation of STAT3 transcriptional activity, we performed luciferase reporter gene assays using a pS TAT3-TA-luc construct in combination with various cDNAs (pcDNA1, G $\alpha_{q}, G \alpha_{q} R C, G \alpha_{11}, G \alpha_{11} Q L, G \alpha_{16}$ and $G \alpha_{16} Q L$ ). As shown in Fig. 2C, both $\mathrm{G}_{\mathrm{q}} \mathrm{RC}$ and $\mathrm{G} \alpha_{11} \mathrm{QL}$ significantly induced STAT3 transcriptional activation as compared to their wildtype and vector controls. Their magnitudes of stimulation were similar to 
that of the positive control G $\alpha_{16} \mathrm{QL}$ (Fig. 2C). Our findings show that activated $G \alpha_{q}, G \alpha_{11}$ and G $\alpha_{16}$ share the ability to induce both STAT3 phosphorylations and STAT3 transcriptional activation.

Since hIP can interact productively with $G \alpha_{q}$ members to activate PLC $\beta$ (Fig. 2A), and that $\mathrm{G}_{\mathrm{q}}$ members can activate STAT3 through the PLC $\beta$ signaling cascades (Lo et al., 2003; Lo and Wong, 2004), cicaprost might well employ the PLC $\beta$ pathway to activate STAT3. To determine if cicaprost-induced STAT3 activation can be mediated along the PLC $\beta$ cascade, HEL cells were pretreated with various inhibitors (10 $\mu \mathrm{M}$ U73122, $10 \mu \mathrm{M}$ KN62 or $100 \mathrm{nM}$ calphostin C) or their inactive analogues (10 $\mu \mathrm{M}$ U73343 or $10 \mu \mathrm{M}$ KN92) for 30 min prior to cicaprost treatment. As shown in Fig. 2D, all inhibitors along the PLC $\beta$ cascade, but not their inactive analogues, clearly attenuated the STAT3 $\mathrm{Tyr}^{705}$ and $\mathrm{Ser}^{727}$ phosphorylations induced by cicaprost, whereas total STAT3 expression levels were unaffected. These results suggest that hIP might utilize PTX-insensitive $G \alpha_{q}, G \alpha_{11}$, or $G \alpha_{16}$ to induce STAT3 phosphorylations via the $\mathrm{PLC} \beta / \mathrm{PKC} / \mathrm{CaMKII}$ cascade and this postulation is in good agreement with the $\mathrm{G} \alpha_{16}$-dependent C5aR-mediated STAT3 activation in HEL cells (Lo et al., 2003). Because the mechanism by which $\mathrm{G} \alpha_{16}$ activates STAT3 is better characterized (Lo et al., 2003), we focused our attention on this $G_{q}$ family member in subsequent experiments for the delineation of cross-talk interactions with $G \alpha_{s}$.

\section{Involvement of Src/JAKs and PI3K signaling pathways in cicaprost-induced STAT3 phosphorylations in HEL cells}

In our previous studies, we noticed distinct differences between cicaprost- and C5a-induced STAT3 phosphorylations in HEL cells (Lo et al., 2003; Lo et al., 2006). The inability of MEK1/2 
to inhibit cicaprost-induced STAT3 $\mathrm{Tyr}^{705}$ phosphorylation in HEL cells (Lo et al., 2006) suggests that hIP may employ signaling pathways different from those of the C5aR (Lo et al., 2003) to regulate STAT3 activity. To further map out the signaling pathways of hIP-mediated STAT3 responses in HEL cells, we examined the ability of cicaprost to stimulate Src and JAK2 phosphorylations in view of their critical roles in both $\mathrm{G \alpha}_{16^{-}}$(Lo et al., 2006) and $\mathrm{G} \alpha_{\mathrm{s}}$-induced (Liu et al., 2006) STAT3 $\mathrm{Tyr}^{705}$ and $\mathrm{Ser}^{727}$ phosphorylations. Crude lysates from the ligand-treated (100 nM cicaprost for 5 to $45 \mathrm{~min}$ ) HEL cells were immunoblotted with anti-c-Src, anti-phospho-c-Src-Tyr ${ }^{416}$, anti-JAK2 and anti-phospho-JAK2-Tyr ${ }^{1006 / 1007}$ antisera. Cicaprost clearly induced Src (Fig. 3A, closed circles) and JAK2 (Fig. 3A, opened circles) phosphorylations in a time-dependent manner. The phosphorylation of JAK2 by cicaprost reached the maximum at 15 min and plateaued thereafter, while c-Src phosphorylation continued to increase at $45 \mathrm{~min}$. These observations indicate that cicaprost can induce the phosphorylations of c-Src and JAK2 in a time-dependent manner.

To delineate the possible requirements of Src/JAKs in hIP-mediated STAT3 $\mathrm{Tyr}^{705}$ and $\operatorname{Ser}^{727}$ activation, HEL cells were pre-incubated with specific inhibitors targeting either Src or JAK2/3. Our results showed that STAT3 $\mathrm{Ser}^{727}$, but not $\mathrm{Tyr}^{705}$, phosphorylation induced by cicaprost was attenuated by specific Src inhibitors, PP1 and PP2 (25 $\mu \mathrm{M})$ whereas the inactive analogue PP3 $(25 \mu \mathrm{M})$ did not inhibit the phosphorylations of STAT3 (Fig. 3B). This is in contrast to the C5a-induced responses (Lo et al., 2003), where both $\operatorname{Ser}^{727}$ and $\mathrm{Tyr}^{705}$ phosphorylations in STAT3 were sensitive to PP1 or PP2 treatment. The inability of Src inhibitors to suppress the STAT3 $\mathrm{Tyr}^{705}$ phosphorylation is, however, in agreement with the Src regulation of $\beta_{2} \mathrm{AR} / \mathrm{G} \alpha_{\mathrm{s}}$-mediated STAT3 responses (Liu et al., 2006). We have also employed $100 \mu \mathrm{M}$ AG490 and $100 \mu \mathrm{g} / \mathrm{ml}$ WHI-P131 in HEL cells to specifically inhibit JAK2 and JAK3, 
respectively. As shown in Fig. 3B, both AG490 and WHI-P131, but not the inactive analogue WHI-P258, suppressed the cicaprost-induced STAT3 $\mathrm{Tyr}^{705}$ and $\mathrm{Ser}^{727}$ phosphorylations. These findings are in line with the $\mathrm{G \alpha}_{16^{-}}$and $\mathrm{G} \alpha_{\mathrm{s}}$-induced STAT3 phosphorylations observed previously (Liu et al., 2006; Lo et al., 2003). The expression level of total STAT3 was unaffected by these kinase inhibitors (Fig. 3B). Collectively, the Src/JAK pathway appears to participate in the cicaprost-induced STAT3 phosphorylations in HEL cells, with considerable resemblance to the regulation elicited by the $\mathrm{G}_{\mathrm{s}}$-coupled $\beta_{2} \mathrm{AR}$ (Liu et al., 2006).

In contrast to Src, given that the participation of PI3K only in $\mathrm{G} \alpha_{\mathrm{s}}$-mediated (Liu et al., 2006) but not $\mathrm{G} \alpha_{16}$-mediated (Lo et al., 2003), STAT3 phosphorylations, the sensitivity to PI3K inhibition might provide clues as to whether $G \alpha_{16}$ or $G \alpha_{\mathrm{s}}$ served as the primary signal for cicaprost-induced STAT3 phosphorylation. Before investigating the possible involvement of PI3K in cicaprost-induced STAT3 activation in HEL cells since, the activity of PI3K was assessed by determining the phosphorylation status of its downstream effector, Akt (Meier and Hemmings, 1999). Again, PTX-treated HEL cells were challenged by $100 \mathrm{nM}$ cicaprost for various time intervals and crude lysates were then immunoblotted with anti-phospho-Akt-Thr ${ }^{308}$ and anti-Akt antisera. As shown in Fig. 3C, maximum induction of Akt phosphorylation was observed by around 30 min of cicaprost incubation. Interestingly, treatment of HEL cells with selective PI3K inhibitors, wortmannin $(100 \mathrm{nM})$ and LY294002 $(10 \mu \mathrm{M})$, abolished cicaprost-induced STAT3 $\mathrm{Ser}^{727}$, but not $\mathrm{Tyr}^{705}$, phosphorylation (Fig. 3D). The effect of the PI3K inhibitors on cicaprost-induced STAT3 phosphorylations resembled neither $\mathrm{G}_{16^{-}}$nor G $\alpha_{s}$-mediated STAT3 responses, but appeared as a hybrid between the two G protein pathways.

The Src and MEK1/2-dependence of $\mathrm{G} \alpha_{16}$-mediated STAT3 $\mathrm{Tyr}^{705}$ phosphorylations is lost 


\section{by co-activation of $\mathrm{G} \alpha_{\text {s }}$}

Inhibition of Src and MEK1/2 attenuated both G $\alpha_{16}$-mediated STAT3 $\mathrm{Tyr}^{705}$ and $\mathrm{Ser}^{727}$ phosphorylations in HEK293 cells (Lo et al., 2003). But the same inhibitors were not effective in suppressing the cicaprost-induced STAT3 $\mathrm{Tyr}^{705}$ phosphorylation (Lo et al., 2006). The resemblance between the inhibitor sensitivity profiles of $\mathrm{G} \alpha_{\mathrm{s}} \mathrm{QL}-$ and cicaprost-induced STAT3 phosphorylations (Liu et al., 2006; Lo et al., 2006) suggests that stimulation of the $\mathrm{G}_{\mathrm{s}}$ pathway may alter the $G_{q / 11}$ and $G_{16}$ pathways in HEL cells. To test whether the alteration of the sensitivity of STAT3 $\operatorname{Tyr}^{705}$ phosphorylation was indeed due to the activation of G $\alpha_{\text {s }}$, HEK293

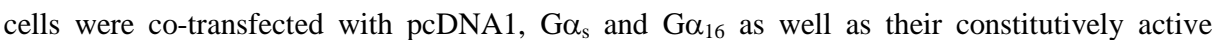
mutants. Wildtype $\mathrm{G} \alpha_{\mathrm{s}}$ and $\mathrm{G} \alpha_{16}$ did not stimulate STAT3 phosphorylation when expressed alone or together (Fig. 4A). The constitutively active $\mathrm{G} \alpha_{\mathrm{s}} \mathrm{QL}$ and $\mathrm{G} \alpha_{16} \mathrm{QL}$ stimulated STAT3 phosphorylation at both $\mathrm{Tyr}^{705}$ and $\mathrm{Ser}^{727}$ sites but there was no further enhancement in phosphorylation upon co-expression of these two mutants (Fig. 4A). As expected, both $\mathrm{Tyr}^{705}$ and $\mathrm{Ser}^{727}$ phosphorylations induced by $\alpha_{16} \mathrm{QL}$ alone were attenuated by $25 \mu \mathrm{M}$ PP1, $25 \mu \mathrm{M}$ PP2 or $10 \mu \mathrm{M}$ U0126, suggesting that Src and MEK1/2 are involved in G $\alpha_{16} \mathrm{QL}$-induced STAT3 $\mathrm{Tyr}^{705}$ and $\mathrm{Ser}^{727}$ phosphorylations. In contrast, STAT3 $\mathrm{Tyr}^{705}$ (but not $\mathrm{Ser}^{727}$ ) phosphorylation became resistant to the suppression of Src and MEK1/2 activity when both G $\alpha_{16} \mathrm{QL}$ and G $\alpha_{\mathrm{s}} \mathrm{QL}$ were co-expressed (Fig. 4A). Co-expression of wildtype $\mathrm{G} \alpha_{\mathrm{s}}$ did not affect the G $\alpha_{16} \mathrm{QL}$-induced STAT3 phosphorylations (data not shown). These data imply that the concomitant activation of $\mathrm{G} \alpha_{\mathrm{s}}$ may provide alternative routes to bypass the requirement of Src and MEK1/2 in STAT3 $\mathrm{Tyr}^{705}$ phosphorylation in a HEK293 recombinant system.

Next, we further examined the regulation of $\mathrm{G} \alpha_{16}$-mediated STAT3 phosphorylations by the G $\alpha_{s}$-dependent signaling pathway in HEL cells. C5aR is a $\mathrm{G}_{\mathrm{i}}$-linked GPCR which is 
endogenously expressed in HEL cells, and which can also induce STAT3 $\mathrm{Tyr}^{705}$ and $\mathrm{Ser}^{727}$ phosphorylations via $G \alpha_{16}$ (Lo et al., 2003). If $\mathrm{G} \alpha_{\mathrm{s}}$ signals can modify the responsiveness of G $\alpha_{16}$-mediated STAT3 phosphorylations to kinase inhibitors as suggested in G $\alpha_{\mathrm{s}} \mathrm{QL} / \mathrm{G} \alpha_{16} \mathrm{QL}-$ expressing HEK293 cells (Fig. 4A), then agents that mimic Go $\alpha_{\mathrm{s}}$ activation should confer upon C5a-induced STAT3 $\mathrm{Tyr}^{705}$ phosphorylation the resistance to PP1, PP2, and U0126. HEL cells were pre-treated with PTX to functionally uncouple C5aR from $\mathrm{G}_{\mathrm{i} / \mathrm{o}}$ proteins, thereby channeling the $\mathrm{C} 5 \mathrm{aR}$ signal to $\mathrm{G} \alpha_{16}$. In agreement with our previous findings (Lo et al., 2003), 100 nM C5a stimulated STAT3 $\operatorname{Tyr}^{705}$ and Ser $^{727}$ phosphorylations in HEL cells, and such responses were abolished by PP1, PP2 or U0126 (Fig. 4B), suggesting that Src and MEK1/2 are involved in this signaling pathway. However, in the presence of $1 \mathrm{mM}$ DB-cAMP, the C5aR-induced phosphorylation of STAT3 at $\mathrm{Tyr}^{705}$ was unaffected by the Src and MEK1/2 inhibitors, despite clear suppression of STAT3 $\operatorname{Ser}^{727}$ phosphorylation by these inhibitors (Fig. 4B). To further confirm the effect of $\mathrm{G} \alpha_{\mathrm{s}}$ signaling in $\mathrm{G} \alpha_{16}$-regulated STAT3 phosphorylations, HEL cells were stimulated with C5a in the absence or presence of cicaprost (100 nM each). Again, the C5a-induced STAT3 $\mathrm{Tyr}^{705}$ phosphorylation became insensitive to Src and MEK1/2 inhibitors in the presence of cicaprost, while STAT3 $\mathrm{Ser}^{727}$ phosphorylation remained fully sensitive to these inhibitors (Fig. 4C). These findings suggest that $\mathrm{G}_{16}$-mediated STAT3 $\mathrm{Tyr}^{705}$ phosphorylation can be altered by $\mathrm{G} \alpha_{\mathrm{s}}$ signals.

\section{Participation of PI3K in hIP-induced STAT3 phosphorylations displays a hybrid of G $\alpha_{16^{-}}$ and $\mathrm{G} \alpha_{\mathrm{s}}$-mediated STAT3 responses}

In contrast to the Src and MEK1/2 inhibitors, the PI3K inhibitors were ineffective in suppressing $\mathrm{G} \alpha_{16}$-mediated STAT3 phosphorylations (Lo et al., 2003) while the same inhibitors 
abolished $\mathrm{G} \alpha_{\mathrm{s}}$-mediated STAT3 phosphorylations (Liu et al., 2006). Interestingly, suppression of PI3K inhibited only the cicaprost-induced STAT3 $\mathrm{Ser}^{727}$ phosphorylation in HEL cells (Fig. 3D).

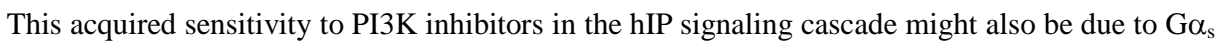
signaling. To address such a possibility, we thus transiently transfected HEK293 cells with pcDNA1, G $\alpha_{s}, G \alpha_{s} \mathrm{QL}, \mathrm{G} \alpha_{16}$ and $\mathrm{G} \alpha_{16} \mathrm{QL}$ individually, or in various combinations. Similar to our previous report (Lo et al., 2003), the G $\alpha_{16}$ QL-induced STAT3 phosphorylations were insensitive to $100 \mathrm{nM}$ wortmannin or $10 \mu \mathrm{M}$ LY294002 (Fig. 5A), indicating that PI3K was not involved in $\mathrm{G}_{16} \mathrm{QL}$-induced STAT3 phosphorylations. Interestingly, STAT3 $\mathrm{Ser}^{727}$, but not $\mathrm{Tyr}^{705}$, phosphorylation was inhibited by the PI3K inhibitors in cells co-expressing G $\alpha_{16} \mathrm{QL}$ and G $\alpha_{\mathrm{s}} \mathrm{QL}$ (Fig. 5A). Again, the differential inhibition of STAT3 $\mathrm{Ser}^{727}$ phosphorylation was not observed when wildtype $G \alpha_{s}$ was co-expressed with $G \alpha_{16} \mathrm{QL}$ (data not shown). These findings demonstrate that $\mathrm{G} \alpha_{16}$-mediated STAT3 phosphorylations could be modified upon co-stimulation of $\mathrm{G} \alpha_{\mathrm{s}}$. This differential sensitivity of $\mathrm{G} \alpha_{\mathrm{s}} \mathrm{QL} / \mathrm{G} \alpha_{16} \mathrm{QL}$-induced STAT3 $\mathrm{Ser}^{727}$ phosphorylation to PI3K inhibitors may represent a hybrid phenotype between $G \alpha_{s} \mathrm{QL}$ and $\mathrm{G} \alpha_{16} \mathrm{QL}$ responses.

Next, we asked if the sensitivity of C5a-induced STAT3 Ser $^{727}$ phosphorylation to PI3K inhibitors can be altered upon treatment of HEL cells with DB-cAMP. As shown in Fig. 5B, C5a-induced STAT3 $\mathrm{Tyr}^{705}$ and $\mathrm{Ser}^{727}$ phosphorylations via endogenous $\mathrm{G} \alpha_{16}$ were not affected by $100 \mathrm{nM}$ wortmannin or $10 \mu \mathrm{M}$ LY294002, which were in line with the results obtained from the transfected HEK293 cells (Fig. 5A). The phosphorylation levels of STAT3 induced by C5a were not affected by the presence of $1 \mathrm{mM}$ DB-cAMP (Fig. 5B). As predicted, in HEL cells co-treated with C5a and DB-cAMP, STAT3 $\mathrm{Ser}^{727}$ phosphorylation became sensitive to inhibition by wortmannin as well as LY294002 (Fig. 5B) while phosphorylation at $\mathrm{Tyr}^{705}$ remained insensitive to the PI3K inhibitors. These data suggest that STAT3 $\operatorname{Ser}^{727}$ phosphorylation is 
modulated by $\mathrm{G}_{\mathrm{s}} / \mathrm{cAMP}$ signals. Moreover, the PI3K inhibitors were able to inhibit STAT3 Ser $^{727}$ phosphorylation in HEL cells which had been co-stimulated with cicaprost and C5a (Fig. 5C). Collectively, these results support the notion that $G_{s}$ signaling can confer PI3K-sensitivity to G $\alpha_{16}$-induced STAT3 Ser ${ }^{727}$ phosphorylation.

\section{Knock-down of $G \alpha_{s}$ confirms its ability to fine-tune $G \alpha_{16}$-mediated STAT3 phosphorylation}

The ability of DB-cAMP to convert C5a-induced STAT3 phosphorylation profile to that of cicaprost-induced responses suggests the participation of $G \alpha_{s}$ in mediating hIP signals. If this hypothesis is correct, then the elimination of $G \alpha_{\mathrm{s}}$-dependent signals should convert the cicaprost responses to a C5a-like profile. Hence, we attempted to knock down the endogenous expression of $\mathrm{G} \alpha_{\mathrm{s}}$ in HEL cells by using small interfering RNA (siRNA) against human $G \alpha_{s}$. As shown in Fig. 6, increasing concentrations of siG $\alpha_{s}$ gradually decreased the endogenous levels of $G \alpha_{s}$ in HEL cells. A substantial reduction (>90\%) of $\mathrm{G} \alpha_{\mathrm{s}}$ by $300 \mathrm{nM}$ siG $\alpha_{\mathrm{s}}$ was observed as compared to control siRNA or untransfected cells. Similar loading was confirmed by the equivalent levels of $\beta$-actin in all samples (Fig. 6).

We then examined the effects of $G \alpha_{s}$ knock-down on cicaprost-induced STAT3 phosphorylations in HEL cells. siG $\alpha_{\mathrm{s}}$-treated HEL cells were incubated with various kinase inhibitors including PP2, U0126, LY294002, wortmannin or DMSO as vehicle for 30 min prior to the cicaprost challenge. As a control, HEL cells were also transfected with the control siRNA (siCtrl). In contrast to control cells, STAT3 $\mathrm{Tyr}^{705}$ phosphorylation in siG $\alpha_{\mathrm{s}}$-treated HEL cells was sensitive to the inhibition of Src and MEK1/2 by PP2 and U0126, respectively (Fig. 7A). The STAT3 Ser $^{727}$ phosphorylation, on the other hand, became insensitive to inhibition of the PI3K pathway by LY294002 or wortmannin. Upon $G \alpha_{s}$ reduction in HEL cells, 
cicaprost-induced STAT3 phosphorylation appears to re-establishes a C5a/G $\alpha_{16}$-mediated STAT3 signaling pattern (Lo et al., 2003).

DB-cAMP can modulate C5a-induced STAT3 phosphorylations (Fig. 4B and 5B) in HEL cells through direct activation of cAMP-dependent pathways. Given that it acts downstream of $\mathrm{G} \alpha_{\mathrm{s}}$, DB-cAMP ought to compensate for the loss of $\mathrm{G} \alpha_{\mathrm{s}}$ signals in siG $\alpha_{\mathrm{s}}$-treated HEL cells. To test this hypothesis, siG $\alpha_{\mathrm{s}}$-treated HEL cells were incubated with various kinase inhibitors and then challenged with C5a in the absence or presence of DB-cAMP. When stimulated with C5a alone, STAT3 $\mathrm{Tyr}^{705}$ and $\mathrm{Ser}^{727}$ phosphorylations were undetectable in cells pretreated with PP2 or U0126, whereas inhibition of PI3K by either LY294002 or wortmannin did not affect the C5a-induced responses (Fig. 7B). These results are identical to C5a-induced responses in normal HEL cells (Lo et al., 2003) and imply that G $\alpha_{\mathrm{s}}$ knock-down does not affect the G $\alpha_{16}$-mediated STAT3 phosphorylations. In the presence of DB-cAMP, C5a-induced STAT3 $\mathrm{Tyr}^{705}$ phosphorylation became insensitive to inhibition of Src and MEK1/2 by PP2 and U0126, respectively, whereas C5a-induced STAT3 $\operatorname{Ser}^{727}$ phosphorylation was suppressed upon inhibition of PI3K (Fig. 7B). The resultant STAT3 phosphorylation profile is identical to that induced by cicaprost (Fig. 3 and Lo et al., 2006) and indicates that DB-cAMP can mimic G $\alpha_{\mathrm{s}}$ signals in siG $\alpha_{\mathrm{s}}$-treated HEL cells.

\section{Effects of various inhibitors on STAT3-dependent luciferase activity in HEK293 cells co-expressing $G \alpha_{s} Q L$ and $G \alpha_{16} Q L$}

Lastly, we examined the effects of co-stimulating $\mathrm{G} \alpha_{\mathrm{s}}$ and $\mathrm{G} \alpha_{16}$ on STAT3 transcriptional activity. HEK293 cells were transiently co-transfected with pcDNA1, G $\alpha_{16}$ and/or G $\alpha_{\mathrm{s}}$ or their corresponding constitutive mutants along with a STAT3-driven luciferase reporter. As shown in 
Fig. 8, HEK293 cells co-expressing $G \alpha_{s} \mathrm{QL}$ and $\mathrm{G} \alpha_{16} \mathrm{QL}$ exhibited increased STAT3-dependent luciferase activity, and the magnitude of the stimulation was similar to that obtained with cells expressing $\mathrm{G} \alpha_{16} \mathrm{QL}$ alone. In contrast to the marked suppression of $\mathrm{G} \alpha_{16} \mathrm{QL}$-induced STAT3-driven luciferase expression by Src and ERK inhibition (Lo et al., 2003), PP1, PP2 and U0126 only partially inhibited STAT3 transcriptional activation induced simultaneously by $\mathrm{G} \alpha_{\mathrm{s}} \mathrm{QL}$ and $\mathrm{G} \alpha_{16} \mathrm{QL}$ (Fig. 8). Furthermore, the attenuation of $\mathrm{G} \alpha_{\mathrm{s}} \mathrm{QL} / \mathrm{G} \alpha_{16} \mathrm{QL}$-induced STAT3 transcriptional activation by wortmannin (Wort) or LY294002 (LY294) was less effective than that with the G $\alpha_{s} \mathrm{QL}$ transfectants (Liu et al., 2006). Consistent with the $\mathrm{G} \alpha_{16} \mathrm{QL}-$ or G $\alpha_{s}$ QL-induced STAT3 responses, inhibition of JAKs by AG490 and WHI-P131 (WHI) almost entirely reduced the $\mathrm{G} \alpha_{\mathrm{s}} \mathrm{QL} / \mathrm{G} \alpha_{16} \mathrm{QL}-$ mediated STAT3-driven luciferase expression (Fig. 8). All inactive analogues of the inhibitors failed to reduce the $\mathrm{G} \alpha_{\mathrm{s}} \mathrm{QL} / \mathrm{G} \alpha_{16} \mathrm{QL}$-induced STAT3-driven luciferase expression; these included U0124, PP3, LY303511 (LY303) and WHI-P258 (WHI-ve). Overall, the inhibitor sensitivity profile of $\mathrm{G} \alpha_{s} \mathrm{QL} / \mathrm{G} \alpha_{16} \mathrm{QL}$-induced STAT3 transcriptional activity was similar to the cicaprost-induced STAT3 phosphorylations. 


\section{DISCUSSION}

The ability of GPCRs to signal via multiple G proteins is fast becoming a rule, and the plethora of G protein signals are often integrated for the regulation of effectors (Lowes et al., 2002). Perhaps due to the opposing nature of $G_{s}$ and $G_{i}$, very few GPCRs can simultaneously stimulate these two $G$ proteins. Yet many $G_{s^{-}}$and $G_{i}$-coupled receptors are efficiently linked to $\mathrm{G}_{\mathrm{q}}$-dependent pathways, especially in hematopoietic cells that express the promiscuous $\mathrm{G}_{14 / 16}$ proteins (Mapara et al., 1995; Wilkie et al., 1991). It is therefore not surprising that hIP can utilize $G_{s}$ and $G_{q / 11 / 16}$ for signal transduction. However, the biological significance of co-stimulating multiple G proteins by hIP is poorly defined. Here, we provide several lines of evidence to support the notion that hIP-mediated activation of STAT3 results from a hybrid signaling between $G \alpha_{s}$ and a $G_{q}$ family member such as $G \alpha_{16}$. The ability of hIP to simultaneously signal via $G_{s}$ and $G_{q}$ produces unique characteristics in the regulation of STAT3 activity, as reflected by the sensitivity of STAT3 $\mathrm{Tyr}^{705}$ and $\mathrm{Ser}^{727}$ phosphorylations to inhibitors of Src, MEK and PI3K.

The ability of hIP to signal via the promiscuous $\mathrm{G} \alpha_{16}$ (Hazari et al., 2004; Mody et al., 2000; Offermanns and Simon, 1995) is not entirely surprising. Likewise, its poor interaction with $G \alpha_{14}$ is consistent with the less promiscuous nature of $\mathrm{G} \alpha_{14}$ (Ho et al., 2001). Since hIP can signal via $\mathrm{G} \alpha_{16}$ (as well as $\mathrm{G} \alpha_{\mathrm{q} / 11}$ ), one would predict that its activation will drive STAT3 activity in HEL cells where both hIP and $\mathrm{G}_{16}$ are expressed. Indeed, cicaprost-stimulated hIP is able to induce STAT3 phosphorylations through PTX-insensitive G proteins in HEL cells (Lo et al., 2006), and the pathway appears to involve PLC $\beta / \mathrm{PKC} / \mathrm{CaMKII}$ signaling (Fig. 2D). As compared to C5a/ $\mathrm{G}_{16}$-mediated STAT3 phosphorylations in the same cell type (Lo et al., 2003), the cicaprost-induced responses are distinctly different in terms of their sensitivity to inhibition of 
MEK1/2 and JNK (Lo et al., 2006). Herein we further noted the distinctive sensitivity of cicaprost-stimulated STAT3 responses to Src and PI3K inhibition. Such differences imply that the mechanisms of action are not identical for cicaprost and C5a. $G \alpha_{s^{-}}$and $G \alpha_{q / 11}$-dependent pathways are the obvious culprits because they are activated by hIP (Chow et al., 2004; Kam et al., 2001) but not by C5aR (Tsu et al., 1995). Among the two possibilities, the G $\alpha_{\mathrm{s}}$-dependent pathway seems more likely since $\mathrm{G \alpha}_{16}$ and $\mathrm{G} \alpha_{q / 11}$ share considerable similarities in their signaling properties. Indeed, G $\alpha_{s} \mathrm{QL}$ is capable of inducing STAT3 activation in HEK293 cells (Liu et al., 2006), while stimulation of endogenuous $G \alpha_{s}$ by CTX or PKA by DB-cAMP significantly promotes STAT3 phosphorylations in HEL cells (Fig. 1B). These results illustrate the likelihood of $\mathrm{G} \alpha_{\mathrm{s}}$ being involved in cicaprost-induced STAT3 activation in HEL cells.

Although it is generally known that $G \alpha_{s}$ and $G \alpha_{16}$ employ different sets of signaling molecules, several signaling intermediates appear to be common in $G \alpha_{\mathrm{s}^{-}}$and $\mathrm{G} \alpha_{16}$-mediated STAT3 activations. JAK participation is crucial in both G $\alpha_{16} \mathrm{QL}-$ (Lo et al., 2003) and G $\alpha_{s}$ QL-induced STAT3 responses (Liu et al., 2006). Indeed, co-stimulation of $G \alpha_{s}$ and $G \alpha_{16}$ by cicaprost in HEL cells promoted JAK2 tyrosine phosphorylation (Fig. 3A). It is conceivable that JAK acts as a potential GPCR-signal integrator for STAT3. Our findings support the participation of JAKs in cicaprost-induced STAT3 phosphorylations because the selective inhibitors of JAK2/3 (AG490 and WHI-P131) suppressed these responses (Fig. 3B). Nevertheless, much remains to be elucidated in terms of the identity and specificity of JAK isoforms as well as their precise mechanism for regulating the STAT3 $\mathrm{Ser}^{727}$ phosphorylation.

Besides JAK, Src and ERK are also important STAT3 regulators in G $\alpha_{\mathrm{s}} \mathrm{QL}-$ and G $\alpha_{16}$ QL-mediated responses (Liu et al., 2006; Lo et al., 2003). Cicaprost can activate both Src (Fig. 3A) and ERK (Lo et al., 2003; Lo et al., 2006) in HEL cells. Yet, the cicaprost-induced 
STAT3 Tyr $^{705}$ phosphorylation was unaffected by blocking Src (Fig. 3B) and MEK/ERK (Lo et al., 2006). Contrarily, G $\alpha_{16}$-induced STAT3 $\mathrm{Tyr}^{705}$ phosphorylation was sensitive to Src or MEK/ERK inhibition (Lo et al., 2003), but such sensitivity was abolished in the presence of DB-cAMP or cicaprost (Fig. 4B and 4C). In HEK293 cells, constitutively active Ga $\alpha_{\mathrm{s}} \mathrm{QL}$ and G $\alpha_{16} \mathrm{QL}$ were employed to mimic the hIP-induced $G \alpha_{s}$ and $G \alpha_{16}$ pathways in HEL cells. G $\alpha_{16}$ QL-induced STAT3 $\mathrm{Tyr}^{705}$ phosphorylation became resistant to PP1/2 or U0126 (Fig. 4A) when $\mathrm{G} \alpha_{\mathrm{s}} \mathrm{QL}$ was coexpressed. In HEL cells, C5a-induced $\mathrm{G} \alpha_{16}$-mediated STAT3 $\mathrm{Tyr}^{705}$ phosphorylation also became resistant to PP1/2 or U0126 in the presence of DB-cAMP (Fig. 4B)

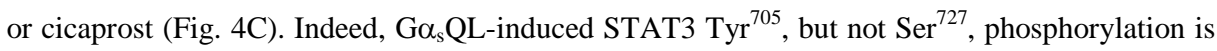
independent of Src and MEK1/2 (Liu et al., 2006). The ability of cicaprost, DB-cAMP and G $\alpha_{s}$ QL to turn off the sensitivity of STAT3 $\mathrm{Tyr}^{705}$ phosphorylation to Src and MEK1/2 inhibitors clearly suggests a fine-tuning role of $G_{s}$ signaling. It should be noted that the $G_{s}$ activation seemingly provides an alternative route for STAT3 $\mathrm{Tyr}^{705}$ phosphorylation via other tyrosine kinases such as Etk (Tsai et al., 2000).

Another noteworthy observation relates to the apparent involvement of PI3K in cicaprost-induced STAT3 $\mathrm{Ser}^{727}$, but not $\mathrm{Tyr}^{705}$, phosphorylation in HEL cells (Fig. 5B). By co-expressing $\mathrm{G} \alpha_{\mathrm{s}} \mathrm{QL}$ and $\mathrm{G} \alpha_{16} \mathrm{QL}$ in HEK293 cells, STAT3 $\mathrm{Ser}^{727}$, but not $\mathrm{Tyr}^{705}$, phosphorylation was suppressed by PI3K inhibitors (Fig. 5A). Similarly, G sathway activation by DB-cAMP (Fig. 5B) or cicaprost (Fig. 5C) permitted suppression of C5a/Ga $\alpha_{16}$-mediated STAT3 Ser $^{727}$ phosphorylation by PI3K inhibitors in HEL cells. This observation is distinctly different from our earlier studies which showed PI3K-independent and -dependent STAT3 phosphorylations by $\mathrm{G} \alpha_{16} \mathrm{QL}$ (Lo et al., 2003) and G $\alpha_{s} \mathrm{QL}$ (Liu et al., 2006), respectively. PI3K indeed plays a critical role in STAT3 Ser ${ }^{727}$ phosphorylation in human T cells (Fung et al., 2003); 
however, little is known about how PI3K regulates STAT3 $\mathrm{Tyr}^{705}$ phosphorylation. This apparent difference between $\mathrm{G} \alpha_{\mathrm{s}} \mathrm{QL}$ - and cicaprost-induced responses is probably due to the simultaneous engagement of $G \alpha_{q / 11 / 16}$ signals, thereby conferring a different profile of inhibitor-sensitivity to cicaprost-induced responses.

A notable feature of $\mathrm{G}_{\mathrm{s}}$-induced changes in STAT3 phosphorylations is the relative resistance of $\mathrm{Tyr}^{705}$ to suppression by the Src kinase inhibitors. It is generally believed that $\mathrm{Tyr}^{705}$ phosphorylation is required for STAT3 transcriptional activity, whereas $\mathrm{Ser}^{727}$ phosphorylation enhances transcriptional activity (Darnell, 1997). Hence, blockade of Src and MEK would partially inhibit $G \alpha_{s}$ QL-induced STAT3 transcriptional activity, as opposed to complete suppressions seen with $\mathrm{G} \alpha_{16} \mathrm{QL}$ - or $\mathrm{G} \alpha_{14} \mathrm{QL}$-induced activity (Lo et al., 2003; Lo and Wong, 2004). Our results do conform to such a postulation (Fig. 8). Further experimentation and analysis are required to fully appreciate the significance of differential phosphorylation of STAT3 on its transcriptional activity.

Furthermore, the dominant role of $\mathrm{G}_{\mathrm{s}}$ in cicaprost-induced STAT3 phosphorylations is clearly demonstrated by the use of small interference RNA targeting $G \alpha_{\mathrm{s}}$ in HEL cells in several aspects. Firstly, upon knock-down of endogenous G $\alpha_{\mathrm{s}}$ in HEL cells (Fig. 6), cicaprost generated a STAT3 phosphorylation pattern similar to the C5aR/G $\alpha_{16}$-mediated responses (Lo et al., 2003); both $\mathrm{Tyr}^{705}$ and $\mathrm{Ser}^{727}$ STAT3 phosphorylations required Src and MEK1/2, but not PI3K (Fig. 7A). Secondly, DB-cAMP (by acting downstream of $G \alpha_{s}$ ) converted the C5aR/G $\alpha_{16}$-mediated STAT3 responses in $\mathrm{G}_{\mathrm{s}}$-deficient HEL cells into ones that resembled cicaprost-induced responses in normal HEL cells (Fig. 7B). It should also be noted that cicaprost could not modulate the C5a-induced STAT3 responses in siG $\alpha_{s}$-treated HEL cells (data not shown), thus 
indicating that the predominant nature of cicaprost over C5a responses in HEL cells (Fig. 4C and 5C) requires $G \alpha_{s}$ signaling.

By summarizing the kinase-dependency profiles of $\mathrm{G \alpha}_{\mathrm{s}^{-}}$and $\mathrm{G} \alpha_{16}$-mediated STAT3 phosphorylation in HEL and transfected HEK293 cells, the aforementioned similarities and differences can be clearly seen (Fig. 9). G $\alpha_{16}$-dependent signaling in HEL cells has an identical kinase-dependency profile as reported previously for $\mathrm{G} \alpha_{16} \mathrm{QL}$ in HEK293 cells (Lo et al., 2003), yet can be converted to an "hIP-like" profile by DB-cAMP treatment. Moreover, in HEK293 cells when both $G \alpha_{s}$ and $G \alpha_{16}$ pathways are simultaneously activated, a hybrid model resembling more closely the $\mathrm{G} \alpha_{\mathrm{s}}$ pathway can be observed (Fig. 10). It should be noted that the proposed models are simplistic views of the actual signaling networks because parallel and alternative pathways may well be involved; for instance, modulation of Src activity by G $\beta \gamma$ (Luttrell et al., 1996). Moreover, the ability of $\mathrm{G}_{\mathrm{s}}$ signals to alter STAT3 regulatory pathways may not be shared by other STAT members. STAT1 can also be phosphorylated upon activation of hIP in HEL cells, but both STAT1 $\mathrm{Tyr}^{701}$ and $\mathrm{Ser}^{727}$ phosphorylations are equally susceptible to inhibition by U0126 (Lo et al., 2006), suggesting an activation mechanism different from that of STAT3. However, it remains to be determined whether hIP-induced STAT1 phosphorylations in HEL cells are in fact $\mathrm{G} \alpha_{\mathrm{s}}$ and/or $\mathrm{G} \alpha_{\mathrm{q} / 11 / 16}$-dependent.

Here, we have highlighted the intricacies of GPCR signaling networks and demonstrated the complexity of regulatory controls of downstream effectors upon activation of multiple G proteins. With an increasingly large number of effectors being regulated by $G$ proteins, one would expect that the co-stimulation of different G proteins may modulate the final cellular responses, especially those involving protein kinase cascades and transcription factors. It has indeed been shown that co-stimulation of $\mathrm{G}_{\mathrm{s}}$ and $\mathrm{G}_{\mathrm{q}}$ pathways can alter the activity of JNK (Chan and Wong, 
2005) and interleukin-4 production in human mast cells (Ryzhov et al., 2006). Furthermore, since $G_{16}$ can also regulate NFkB via Src and MEK/ERK (Liu and Wong, 2004), it would be interesting to determine if $\mathrm{G}_{\mathrm{s}}$ co-stimulation could similarly alter the sensitivity of NFKB to inhibitors of these kinases. Ultimately, the dominant role of $G \alpha_{s}$ over $G \alpha_{16}$ signaling to STAT3 may provide the basis for determining the functional outcome when HEL cells are co-stimulated by $\mathrm{G} \alpha_{s^{-}}$and $\mathrm{G} \alpha_{16}$-coupled GPCRs. 


\section{REFERENCES}

Belch JJ, McLaren M, Lau CS, Mackay IR, Bancroft A, McEwen J and Thompson JM (1993) Cicaprost, an orally active prostacyclin analogue: its effects on platelet aggregation and skin blood flow in normal volunteers. Br J Clin Pharmacol 35:643-647.

Belmonte N, Phillips BW, Massiera F, Villageois P, Wdziekonski B, Saint-Marc P, Nichols J, Aubert J, Saeki K, Yuo A, Narumiya S, Ailhaud G and Dani C (2001) Activation of extracellular signal-regulated kinases and CREB/ATF-1 mediate the expression of CCAAT/enhancer binding proteins beta and -delta in preadipocytes. Mol Endocrinol 15:2037-2049.

Chan AS and Wong YH (2005) $\mathrm{G}_{\mathrm{q}}$-mediated activation of c-Jun N-terminal kinase by the gastrin-releasing peptide-preferring bombesin receptor is inhibited upon costimulation of the $\mathrm{G}_{\mathrm{s}}$-coupled dopamine $\mathrm{D}_{1}$ receptor in COS-7 cells. Mol Pharmacol 68:1354-1364.

Chow KB, Jones RL and Wise H (2004) Agonists can discriminate between cloned human and mouse prostacyclin receptors. Prostaglandins Leukot Essent Fatty Acids 70:423-429.

Chu KM, Chow KB, Wong YH and Wise H (2004) Prostacyclin receptor-mediated activation of extracellular signal-regulated kinases 1 and 2. Cell Signal 16:477-486.

Clark RD, Jahangir A, Severance D, Salazar R, Chang T, Chang D, Jett MF, Smith S and Bley K (2004) Discovery and SAR development of 2-(phenylamino) imidazolines as prostacyclin receptor antagonists. Bioorg Med Chem Lett 14:1053-1056.

Daaka Y, Luttrell LM and Lefkowitz RJ (1997) Switching of the coupling of the $\beta_{2}$-adrenergic receptor to different G proteins by protein kinase A. Nature 390:88-91.

Darnell JE, Jr. (1997) STATs and gene regulation. Science 277:1630-1635.

Fung MM, Rohwer F and McGuire KL (2003) IL-2 activation of a PI3K-dependent STAT3 serine phosphorylation pathway in primary human T cells. Cell Signal 15:625-636.

Hasseldine AR, Harper EA and Black JW (2003) Cardiac-specific overexpression of human $\beta_{2}$ adrenoceptors in mice exposes coupling to both $\mathrm{G}_{\mathrm{s}}$ and $\mathrm{G}_{\mathrm{i}}$ proteins. $\mathrm{Br} \mathrm{J}$ Pharmacol 138:1358-1366.

Hazari A, Lowes V, Chan JH, Wong CS, Ho MK and Wong YH (2004) Replacement of the $\alpha 5$ helix of $\mathrm{G} \alpha_{16}$ with Galphas-specific sequences enhances promiscuity of $\mathrm{G} \alpha_{16}$ toward $\mathrm{G}_{\mathrm{s}}$-coupled receptors. Cell Signal 16:51-62.

Ho MK, Yung LY, Chan JS, Chan JH, Wong CS and Wong YH (2001) G $\alpha_{14}$ links a variety of $\mathrm{G}_{\mathrm{i}^{-}}$ and $\mathrm{G}_{\mathrm{s}}$-coupled receptors to the stimulation of phospholipase C. Br J Pharmacol 132:1431-1440.

Kam Y, Chow KB and Wise H (2001) Factors affecting prostacyclin receptor agonist efficacy in different cell types. Cell Signal 13:841-847.

Liu AM, Lo RK, Wong CS, Morris C, Wise H and Wong YH (2006) Activation of STAT3 by G⿰丿⺄⿱ distinctively requires protein kinase A, JNK, and phosphatidylinositol 3-kinase. J Biol Chem 281:35812-35825.

Liu AM and Wong YH (2004) $\mathrm{G}_{16}$-mediated activation of nuclear factor $\kappa \mathrm{B}$ by the adenosine $\mathrm{A}_{1}$ receptor involves c-Src, protein kinase C, and ERK signaling. J Biol Chem 279:53196-53204.

Liu AM and Wong YH (2005) $\mu$-opioid receptor-mediated phosphorylation of IкB kinase in human neuroblastoma SH-SY5Y cells. Neurosignals 14:136-142.

Lo RK, Cheung H and Wong YH (2003) Constitutively active G $\alpha_{16}$ stimulates STAT3 via a c-Src/JAK- and ERK-dependent mechanism. J Biol Chem 278:52154-52165. 
Lo RK, Wise H and Wong YH (2006) Prostacyclin receptor induces STAT1 and STAT3 phosphorylations in human erythroleukemia cells: a mechanism requiring PTX-insensitive G proteins, ERK and JNK. Cell Signal 18:307-317.

Lo RK and Wong YH (2004) Signal transducer and activator of transcription 3 activation by the $\delta$-opioid receptor via $\mathrm{G}_{14}$ involves multiple intermediates. Mol Pharmacol 65:1427-1439.

Lowes VL, Ip NY and Wong YH (2002) Integration of signals from receptor tyrosine kinases and G protein-coupled receptors. Neurosignals 11:5-19.

Luttrell LM, Hawes BE, van Biesen T, Luttrell DK, Lansing TJ and Lefkowitz RJ (1996) Role of c-Src tyrosine kinase in G protein-coupled receptor- and G $\beta \gamma$ subunit-mediated activation of mitogen-activated protein kinases. J Biol Chem 271:19443-19450.

Mapara MY, Bommert K, Bargou RC, Leng C, Beck C, Ludwig WD, Gierschik P and Dorken B (1995) $\mathrm{G}$ protein subunit $\mathrm{G} \alpha_{16}$ expression is restricted to progenitor B cells during human B-cell differentiation. Blood 85:1836-1842.

McAdam BF, Catella-Lawson F, Mardini IA, Kapoor S, Lawson JA and FitzGerald GA (1999) Systemic biosynthesis of prostacyclin by cyclooxygenase (COX)-2: the human pharmacology of a selective inhibitor of COX-2. Proc Natl Acad Sci U S A 96:272-277.

Meier R and Hemmings BA (1999) Regulation of protein kinase B. J Recept Signal Transduct Res 19:121-128.

Miggin SM and Kinsella BT (2002) Investigation of the mechanisms of G protein: effector coupling by the human and mouse prostacyclin receptors. Identification of critical species-dependent differences. J Biol Chem 277:27053-27064.

Mody SM, Ho MK, Joshi SA and Wong YH (2000) Incorporation of $G \alpha_{z}$-specific sequence at the carboxyl terminus increases the promiscuity of $\mathrm{G \alpha}_{16}$ toward $\mathrm{G}_{\mathrm{i}}$-coupled receptors. Mol Pharmacol 57:13-23.

Narumiya S, Sugimoto Y and Ushikubi F (1999) Prostanoid receptors: structures, properties, and functions. Physiol Rev 79:1193-1226.

Offermanns S and Simon MI (1995) $\mathrm{G \alpha}_{15}$ and $\mathrm{G \alpha}_{16}$ couple a wide variety of receptors to phospholipase C. J Biol Chem 270:15175-15180.

Ram PT, Horvath CM and Iyengar R (2000) STAT3-mediated transformation of NIH-3T3 cells by the constitutively active Q205L G $\alpha_{0}$ protein. Science 287:142-144.

Rubin LJ, Groves BM, Reeves JT, Frosolono M, Handel F and Cato AE (1982) Prostacyclin-induced acute pulmonary vasodilation in primary pulmonary hypertension. Circulation 66:334-338.

Ryzhov S, Goldstein AE, Biaggioni I and Feoktistov I (2006) Cross-talk between $\mathrm{G}_{\mathrm{s}}$ - and $\mathrm{G}_{\mathrm{q}}$-coupled pathways in regulation of interleukin- 4 by $A_{2 B}$ adenosine receptors in human mast cells. Mol Pharmacol 70:727-735.

Sasaki Y, Takahashi T, Tanaka I, Nakamura K, Okuno Y, Nakagawa O, Narumiya S and Nakao K (1997) Expression of prostacyclin receptor in human megakaryocytes. Blood 90:1039-1046.

Schoneberg T, Kostenis E, Liu J, Gudermann T and Wess J (1998) Molecular aspects of vasopressin receptor function. Adv Exp Med Biol 449:347-358.

Tsai YT, Su YH, Fang SS, Huang TN, Qiu Y, Jou YS, Shih HM, Kung HJ and Chen RH (2000) Etk, a Btk family tyrosine kinase, mediates cellular transformation by linking Src to STAT3 activation. Mol Cell Biol 20:2043-2054.

Tsu RC, Allen RA and Wong YH (1995) Stimulation of type II adenylyl cyclase by 
chemoattractant formyl peptide and C5a receptors. Mol Pharmacol 47:835-841.

Wilkie TM, Scherle PA, Strathmann MP, Slepak VZ and Simon MI (1991) Characterization of G-protein $\alpha$ subunits in the $\mathrm{G}_{\mathrm{q}}$ class: expression in murine tissues and in stromal and hematopoietic cell lines. Proc Natl Acad Sci U S A 88:10049-10053.

Wise H (2003) Multiple signalling options for prostacyclin. Acta Pharmacol Sin 24:625-630.

Wu H, Shen HW, Wu TF, Brass LF and Sung KC (2002) Extracellular signal-regulated kinases and $\mathrm{G}$ protein-coupled receptors in megakaryocytic human erythroleukemia cells: selective activation, differential regulation, and dissociation from mitogenesis. $J$ Pharmacol Exp Ther 300:339-345.

Yung LY, Joshi SA, Chan RY, Chan JS, Pei G and Wong YH (1999) $\mathrm{G}_{\mathrm{L} 1}\left(\mathrm{G \alpha}_{14}\right)$ couples the opioid receptor-like1 receptor to stimulation of phospholipase C. J Pharmacol Exp Ther 288:232-238.

Zucker TP, Bonisch D, Hasse A, Grosser T, Weber AA and Schror K (1998) Tolerance development to antimitogenic actions of prostacyclin but not of prostaglandin E1 in coronary artery smooth muscle cells. Eur J Pharmacol 345:213-220. 


\section{ACKNOWLEDGEMENTS}

This work was supported in part by grants from the Research Grants Council of Hong Kong (HKUST 6120/04M and HKUST 3/03C), the University Grants Committee (AoE/B-15/01), and the Hong Kong Jockey Club. YHW was a recipient of the Croucher Senior Research Fellowship. 


\section{FIGURE LEGENDS}

Fig. 1. (A) The involvement of hIP receptor in cicaprost-induced STAT3 phosphorylations in HEL cells. HEL cells were challenged with $100 \mathrm{nM}$ cicaprost in the presence or absence of the antagonist, CAY10449 (1 $\mu \mathrm{M})$ for another $30 \mathrm{~min}$ and cell lysates were immunoblotted with anti-phospho-STAT3-Tyr ${ }^{705}$ (upper panel), anti-phospho-STAT3-Ser ${ }^{727}$ (middle panel) or anti-STAT3 (lower panel) antiserum. (B) The participation of $\mathrm{G} \alpha_{s} / \mathrm{AC} / \mathrm{PKA}$ pathway in cicaprost-induced STAT3 phosphorylations in HEL cells. HEL cells were treated with various reagents including $10 \mu \mathrm{M}$ H-89, $100 \mu \mathrm{M}$ Rp-cAMPS (Rp), DB-cAMP (DB) for 30 min, 100 ng/ml CTX for 4 h or vehicle control (0.1\% DMSO). Cell lysates were collected and analyzed. The result of the densitometric analysis is shown above the immunoblots; open bars represent the $\mathrm{Tyr}^{705}$ phosphorylation level of STAT3 whereas closed bars are the $\mathrm{Ser}^{727}$ phosphorylation level of STAT3. Numerical values shown above the immunoreactive bands represent relative intensities of STAT3 phosphorylations expressed as a ratio of the basal level (set as 1.0). *, STAT3 phosphorylations were significantly higher than the basal value (one-way ANOVA with Dunnett's post-tests, $p<0.05)$. The immunoblots shown represent one of three sets; two other sets yielded similar results.

Fig. 2. The coupling of hIP to $G \alpha_{q}, G \alpha_{11}, G \alpha_{16}$, but not $G \alpha_{14}$, in HEK293 cells and the involvement of their downstream PLC $\beta / \mathrm{PKC/CaMKII} \mathrm{cascade} \mathrm{in} \mathrm{cicaprost-induced} \mathrm{STAT3}$ phosphorylations in HEL cells. (A) HEK293 cells were co-transfected with hIP in combination with pcDNA1, $G \alpha_{q}, G \alpha_{11}, G \alpha_{16}$ or $G \alpha_{14}$. (B) HEK293 cells were transiently transfected with pcDNA1, $G \alpha_{q}, G \alpha_{q} R C, G \alpha_{11}, G \alpha_{11} Q L, G \alpha_{16}$ and $G \alpha_{16} Q L$. Transfectants were assayed for 
$\left[{ }^{3} \mathrm{H}\right]$ inositol phosphates accumulation. The inositol phosphate levels were determined as the average ratio of $\left[{ }^{3} \mathrm{H}\right]$ inositol phosphates to the total $\left[{ }^{3} \mathrm{H}\right]$ inositol species. *, Inositol phosphate formations induced by cicaprost or constitutively active mutants were significantly higher than the basal value (one-way ANOVA with Dunnett's post-tests, $p<0.05$ ). ${ }^{\#}$, Inositol phosphate formations induced by cicaprost-treated cells coexpressing hIP in combination with $G \alpha_{q}$, G $\alpha_{11}$ or G $\alpha_{16}$ were significantly higher than those obtained with pcDNA1 (one-way ANOVA with Dunnett's post-tests, $p<0.05$ ). (C) For the luciferase assay, pSTAT3-TA-luc cDNA was transiently co-transfected into HEK293 cells along with pcDNA1, $G \alpha_{q}, G \alpha_{q} R C, G \alpha_{11}, G \alpha_{11} Q L$, $\mathrm{G} \alpha_{16}$ or $\mathrm{G} \alpha_{16} \mathrm{QL}$. The luciferase activity in the cell lysate was expressed as fold stimulation of the pcDNA1 control. Data shown represent the mean \pm SEM from four separate experiments performed in triplicates. *, STAT3 transcriptional activations induced by constitutively active mutants were significantly higher than pcDNA1 (one-way ANOVA with Dunnett's post-tests, $p$ < 0.05). (D) HEL cells were exposed to $10 \mu \mathrm{M}$ U73122, U73343, KN62, KN92, $100 \mathrm{nM}$ calphostin C (Cal. C) or vehicle control (0.1\% DMSO) for 30 min followed by cicaprost (100 nM) for 30 min. Cell lysates were collected and analyzed as described in Fig. 1.

Fig. 3. The activation and involvement of Src/JAKs and PI3K pathway. (A, C) HEL cells were challenged with $100 \mathrm{nM}$ cicaprost for different periods of time. Cell lysates were resolved and analyzed by anti-phospho-c-Src $\mathrm{Tyr}^{416}$, anti-c-Src, anti-phospho-JAK2 $\mathrm{Tyr}^{1007 / 1008}$, anti-JAK2 antibodies, anti-phospho-Akt $\mathrm{Thr}^{308}$ and anti-Akt. Closed circles represent c-Src (A) or Akt (C) phosphorylation while open circles are for JAK2 phosphorylation (A). Numerical values shown above the immunoreactive bands represent relative intensities of cicaprost-induced Akt phosphorylations expressed as a ratio of the basal level (set as 1.0). (B,D) HEL cells were 
pre-incubated with $25 \mu \mathrm{M}$ PP1, PP2, PP3, $100 \mu \mathrm{M}$ AG490, $100 \mu \mathrm{g} / \mathrm{ml}$ WHI-P131 (WHI), WHI-P258 (WHI-ve), $10 \mu \mathrm{M}$ wortmannin (Wort), $100 \mathrm{nM} \mathrm{LY294002} \mathrm{(LY294)} \mathrm{or} \mathrm{vehicle}$ control (0.1\% DMSO) for $30 \mathrm{~min}$ and followed by $100 \mathrm{nM}$ cicaprost for another $30 \mathrm{~min}$. Cell lysates were analyzed as described in Fig. 1.

Fig. 4. Activation of $\mathrm{G} \alpha_{\mathrm{s}}$ pathway alters the sensitivity of $\mathrm{G}_{16}$-mediated STAT3 $\mathrm{Tyr}^{705}$ phosphorylation to inhibitors of c-Src and MEK1/2. (A) HEK293 cells were transiently co-transfected with pcDNA1, G $\alpha_{s}, G \alpha_{s} \mathrm{QL}, \mathrm{G} \alpha_{16}$ and/or $\mathrm{G} \alpha_{16} \mathrm{QL}$. Transfectants were serum starved overnight and further pre-treated with $25 \mu \mathrm{M}$ PP1, PP2 or $10 \mu \mathrm{M}$ U0126 for 30 min at $37^{\circ} \mathrm{C}$. Cell lysates were analyzed as described in Fig. 2B. (B and C) HEL cells were pre-treated with $25 \mu \mathrm{M}$ PP1, PP2 or $10 \mu \mathrm{M}$ U0126 for $30 \mathrm{~min}$ at $37^{\circ} \mathrm{C}$ and then incubated with (B) $100 \mathrm{nM}$ C5a and $1 \mathrm{mM}$ DB-cAMP or (C) C5a and $100 \mathrm{nM}$ cicaprost for another $30 \mathrm{~min}$ at $37^{\circ} \mathrm{C}$. Cell lysates were immunoblotted with anti-phospho-STAT3-Tyr ${ }^{705}$ (upper panel), anti-phospho-STAT3-Ser ${ }^{727}$ (middle panel) or anti-STAT3 (lower panel) antiserum. Cell lysates were analyzed as described in Fig. 1.

Fig. 5. Participation of PI3K in hIP-induced STAT3 phosphorylations displays a hybrid of G $\alpha_{16}$ - and $\mathrm{G} \alpha_{\mathrm{s}}$-mediated STAT3 responses. (A) HEK293 cells were transiently co-transfected with pcDNA1, G $\alpha_{s}, G \alpha_{s} \mathrm{QL}, \mathrm{G} \alpha_{16}$ and/or $\mathrm{G} \alpha_{16} \mathrm{QL}$. Transfectants were serum starved overnight and further pre-treated with $100 \mathrm{nM}$ wortmannin (Wort) or $10 \mu \mathrm{M}$ LY294002 (LY294) for 30 min at $37^{\circ} \mathrm{C}$. Cell lysates were analyzed as described in Fig. 2B. (B and C) HEL cells were pre-treated with $100 \mathrm{nM}$ wortmannin or $10 \mu \mathrm{M}$ LY294002 for $30 \mathrm{~min}$ at $37^{\circ} \mathrm{C}$ and then incubated with (B) $100 \mathrm{nM} \mathrm{C5a}$ and $1 \mathrm{mM}$ DB-cAMP or (C) C5a and $100 \mathrm{nM}$ cicaprost for another $30 \mathrm{~min}$ 
at $37^{\circ} \mathrm{C}$. Cell lysates were analyzed as described in Fig. 1.

Fig. 6. Knockdown of endogenous $\mathrm{G} \alpha_{\mathrm{s}}$ in HEL cells. HEL cells were transiently transfected with different concentrations of siRNA targeting $G \alpha_{s}\left(s i G \alpha_{s}\right)$, control siRNA (siCtrl) or water (Ctrl). Cell lysates were analyzed as described in Fig. 1.

Fig. 7. Agonist-induced STAT3 phosphorylations in $\mathrm{G}_{\mathrm{s}}$-deficient HEL cells. (A) HEL cells were transfected with $300 \mathrm{nM}$ siG $\alpha_{\mathrm{s}}$ or siCtrl and the transfectants were serum starved for $4 \mathrm{~h}$ before pre-treated with $25 \mu \mathrm{M}$ PP2, $10 \mu \mathrm{M}$ U0126, LY294002 (LY294), 100 nM wortmannin (Wort), or vehicle $(0.1 \% \mathrm{DMSO})$ for $30 \mathrm{~min}$ at $37^{\circ} \mathrm{C}$. Where indicated, cells were subsequently challenged with $100 \mathrm{nM}$ cicaprost for $30 \mathrm{~min}$. (B) HEL cells were transfected with $300 \mathrm{nM}$ siG $\alpha_{\mathrm{s}}$ and treated as in (A). Cells were then stimulated with $100 \mathrm{nM}$ C5a for $30 \mathrm{~min}$ in the absence or presence of 1 mM DB-cAMP. Cell lysates were analyzed as described in Fig. 1.

Fig. 8. Differential regulation of $\mathrm{G} \alpha_{16} \mathrm{QL}-$ and $\mathrm{G} \alpha_{\mathrm{s}} \mathrm{QL}$-induced STAT3-driven transcriptional activation by MEK1/2, c-Src, PI3K, and JAKs in HEK293 cells. HEK293 cells were transiently co-transfected with pSTAT3-TA-luc in combination with pcDNA1, G $\alpha_{s}, \mathrm{G} \alpha_{\mathrm{s}} \mathrm{QL}$, $\mathrm{G} \alpha_{16}$ and/or $\mathrm{G} \alpha_{16} \mathrm{QL}$. Cells were serum starved and further treated with $10 \mu \mathrm{M}$ U0126, U0124, LY294002 (LY294), LY303511 (LY303), 25 M PP1, PP2, PP3, 100 nM wortmannin (Wort), $100 \mu \mathrm{M}$ AG490, $100 \mu \mathrm{g} / \mathrm{ml}$ WHI-P131 (WHI) or WHI-P258 (WHI-ve) or vehicle control (0.1\% DMSO) for overnight. Cell lysates were analyzed as described in Fig. 2C. Data shown represent the mean \pm SEM from four separate experiments performed in triplicates. *, STAT3 transcriptional activations were significantly higher than the pcDNA1 control (one-way ANOVA 


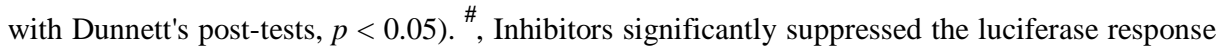
as compared to the vehicle control (one-way ANOVA with Dunnett's post-tests, $p<0.05$ ).

Fig. 10. A mechanistic model of $\mathrm{G}_{16^{-}}$and $\mathrm{G} \alpha_{\mathrm{s}}$-mediated STAT3 $\mathrm{Tyr}^{705}$ and $\mathrm{Ser}^{727}$ phosphorylations. The proposed mechanistic model is based on the known signaling properties and abilities of various signaling components to regulate their respective targets. Five tiers of signaling components are depicted based on their relative proximity to Ga activation: PLC $\beta / P K C$ and AC/PKA, PI3K, Src and MEK. These signaling components are drawn in either hexagons or rectangles, denoting their regulations via $G \alpha_{s}$ or $G \alpha_{16}$ respectively. A hexagon within a rectangle indicates a signaling molecule with the capacity to be regulated simultaneously by $\mathrm{G} \alpha_{\mathrm{s}}$ and $\mathrm{G} \alpha_{16}$. Since JNK participation upon the co-stimulation of $\mathrm{G} \alpha_{\mathrm{s}}$ and G $\alpha_{16}$ is illustrated to be cell line specific, signaling cascades revealed from HEL cells or HEK 293 cells are differently depicted in a white or grey block respectively whereas overlapped area indicates the $\mathrm{G} \alpha_{16}$-mediated pathway commonly observed in HEK293 and HEL cells. 